\title{
Editorial
}

\section{Crystal Strengths at Micro- and Nano-Scale Dimensions}

\author{
Ronald W. Armstrong $1, * \mathbb{1}$ and Wayne L. Elban ${ }^{2}$ \\ 1 Department of Mechanical Engineering, University of Maryland, College Park, MD 20742, USA \\ 2 Department of Engineering, Loyola University Maryland, Baltimore, MD 21210, USA; welban@loyola.edu \\ * Correspondence: rona@umd.edu
}

Received: 3 February 2020; Accepted: 3 February 2020; Published: 5 February 2020

check for updates

\begin{abstract}
Higher strength levels, achieved for dimensionally-smaller micro- and nano-scale materials or material components, such as MEMS devices, are an important enabler of a broad range of present-day engineering devices and structures. Beyond such applications, there is an important effort to understand the dislocation mechanics basis for obtaining such improved strength properties. Four particular examples related to these issues are described in the present report: (1) a compilation of nano-indentation hardness measurements made on silicon crystals spanning nano- to micro-scale testing; (2) stress-strain measurements made on iron and steel materials at micro- to nano-crystal (grain size) dimensions; (3) assessment of small dislocation pile-ups relating to Griffith-type fracture stress vs. crack-size calculations for cleavage fracturing of $\alpha$-iron; and (4) description of thermally-dependent strain rate sensitivities for grain size strengthening and weakening for macroto micro- to nano-polycrystalline copper and nickel materials.
\end{abstract}

Keywords: crystal strength; micro-crystals; nano-crystals; nano-polycrystals; nano-wires; whiskers; pillars; dislocations; hardness; crystal size dependencies; fracture; strain rate sensitivity

\section{Introduction}

To underscore the relevance of the current topic, a number of example engineering-based references are provided for micro- and nano-crystal mechanical property measurements and the applications of them [1-5]. In brief, the topics relate to crystal size effects in manufacturing; strength measurements relating to MEMS applications; micro-forming of foils; nano-metric machining defects; and advanced machine tool manufacturing. Such observations involving extremely small dimensionally-dependent mechanical property measurements have followed a pioneering report by Brenner [6] of greatly-enhanced strength levels being achieved for smaller diameter "whisker" materials. This was later established for nano-grained steel wire [7], micro-pillar $\alpha$-iron [8], and copper [9] materials. The strength levels have been attributed either to higher applied stresses being needed to nucleate individual dislocations within a dislocation-free environment or because of the need for internal stress concentrations to be produced by small dislocation pile-ups [10-12], for example, as established in the description of higher micro-hardness levels reached for nano-grained nickel material [13].

Here, we consider four example cases in more detail, spanning micro- and nano-scale strength levels and their connection with conventional crystal strength properties, as follows: (1) hardness-based nano-indentation load, $P$, values vs. corresponding respective contact diameters, $d_{i}$, for silicon crystals; (2) theoretical-limiting strength levels achieved for the mentioned ultrafine grain size iron and steel materials; (3) dislocation pile-up characterizations of strength levels at nano-scale dimensions relating to the Griffith-based theory of brittle cleavage fracturing; and (3) order-of-magnitude increases in the thermally-dependent strain rate sensitivity properties of nano-crystalline copper and nickel materials associated both with grain size strengthening and grain size-dependent weakening behaviors, in the latter case, connected most often with high temperature creep behavior. 


\section{Elastic, Plastic, and Cracking Aspects of Crystal Nano-Indentations}

Figure 1 provides a background $\log / \log$ compilation of indentation load, $P$, vs. surface-projected contact diameter, $d$, spanning a range from pioneering nano-indentation measurements to micro-scale indentation fracture mechanics test results obtained on silicon crystals, as identified in the top-left corner of the figure [14]. The figure was constructed to illustrate a $d^{3}$ dependence of load for elastic contact in pioneering nano-indentation measurements made by Pethica, Hutchings, and Oliver [15], as compared with an expected $d^{2}$ dependence for a constant material hardness; $D$ is the actual or effective spherical tip diameter for each indentation. The $d_{c}^{3 / 2}$ dependence applies for crack tip-to-crack tip measurements across the enclosed indentations.

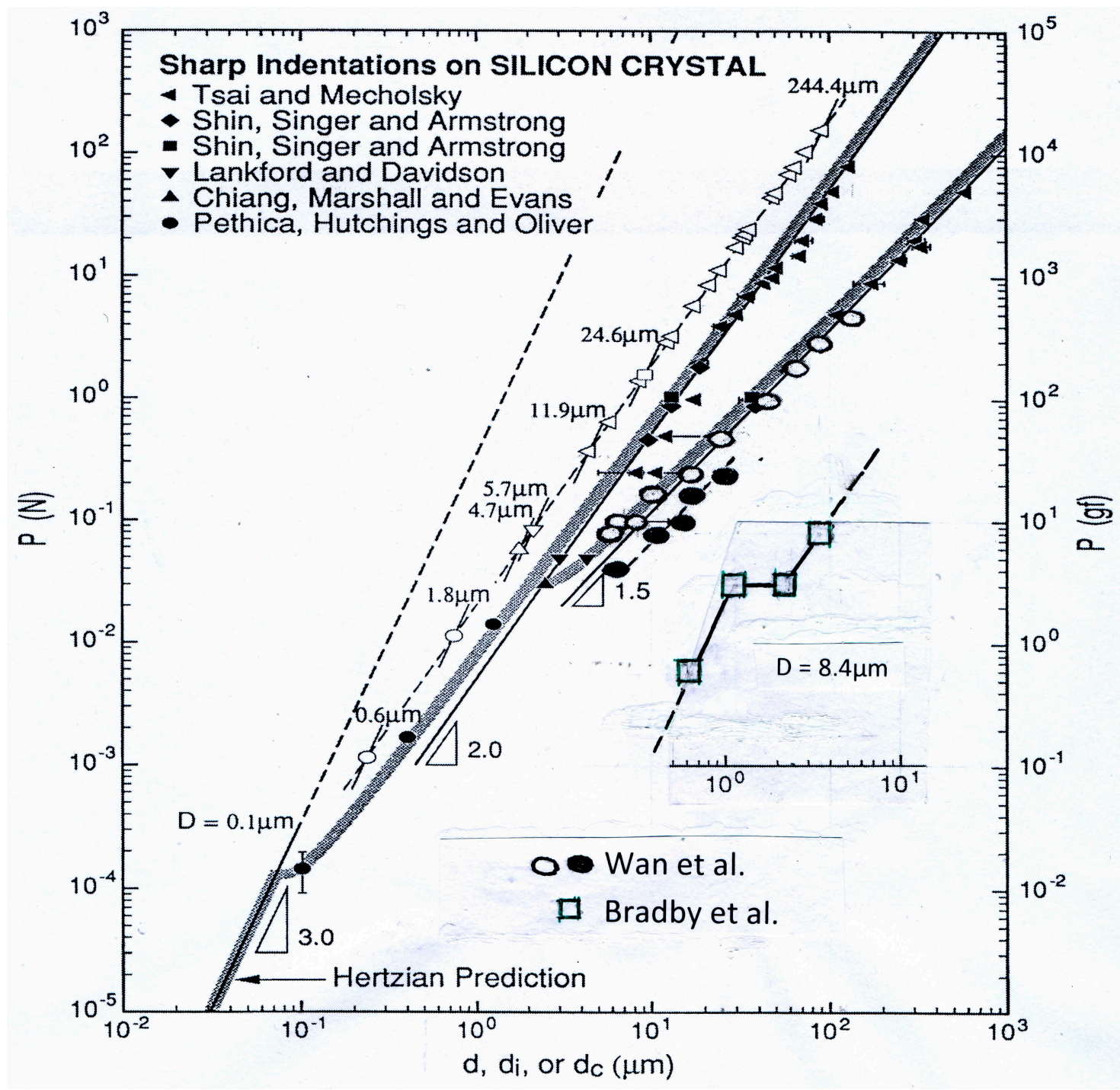

Figure 1. Load, $P$, vs. either elastic contact diameter, $d_{e}$, plastic diamond pyramid diagonal, $d_{d}$, or tip-to-tip crack length, $d_{c}$, for silicon crystal indentations [14], and including additional cracking [16] and inset elastic-plastic spherical Berkovich-type nano-indentation measurements [17]. 
In Figure 1, more recently added open- and closed-ellipsoidal points [16] have covered many of the earlier data points on the $d^{3 / 2}$ fracture mechanics dependence and, likewise, the inset open-square points [17] for both elastic, $d_{e}{ }^{3}$, and plastic, $d_{p}{ }^{2}$, Berkovich spherically-tipped nano-indentations would have significantly overlapped the previously established hardness dependence. Thus, these points that illustrate a significant "pop-in" behavior at initial plastic yield have been shifted on the abscissa scale for clarity. Close examination of the deviation from the labeled $d^{2}$ dependence in Figure 1 shows that an increasing hardness applies for a smaller indentation size. Calculations of the stress-strain behaviors both at the onset of plastic yielding and follow-on nano-indentation strain hardening behaviors have been reported very recently for $\mathrm{NaCl}, \mathrm{MgO}$, and copper crystals [18], tungsten crystals [19], ammonium perchlorate, and $\alpha$-iron crystals [20]. Beyond the well-established determination of very high flow stress levels for initial plastic yielding, whether gradual or of pop-in type, the plastic strain hardening behavior has also been shown to be exceptionally high. The dimensionally smaller plastic deformation zones account for both higher values of initial yielding and subsequent flow on the basis of the smaller dislocation line lengths and their interactions.

\section{Crystal (Grain) Size-Dependent Strengths}

Brenner [6] found an inverse dependence of strength on the specimen wire diameter for $\alpha$-iron and copper whiskers. The same dependence has been found for integrated circuit-connected measurements on gold micro-wires [21] as well as for thin copper wires [22] and other nickel nano-pillar [23] materials, also with consideration taken into account of the nano-polycrystal grain structures. The status of nano-polycrystal micro-pillar strength properties have been reviewed by Shahbeyk et al. [24]. Kiener et al. [25] have provided an analysis of the strength properties on the basis of the small volumes of the materials that were tested.

Figure 2 illustrates on an expanded abscissa scale a further connection of the size dependence described previously for a compilation of strength properties obtained on conventional and ultrafine crystal (grain) size of $\alpha$-iron and steel materials [26]. In the figure, the continuous slightly curved line is an extrapolation of the Hall-Petch (H-P) inverse square root of grain size measured at ambient temperature for a number of steel materials. The filled-square points connected by a dashed line just below the extrapolated H-P dependence are pioneering measurements reported for patented eutectoid steel wire materials. The filled triangle points were also obtained more recently for eutectoid steel wire materials but at smaller effective grain sizes as is indicated as well for the filled circle points that were obtained for ball-milled $\alpha$-iron material. The topmost filled diamond point is a latest measurement reported by Li et al. [7] for severely drawn eutectoid material.

Of particular importance in Figure 2 is a dot-dashed dislocation pile-up model description of the Hall-Petch dependence fitted to the reported $\mathrm{H}-\mathrm{P}$ parameters at larger grain sizes and which dependence is shown to transition at ultrafine grain size from an $\ell^{-1 / 2}$ to an $\ell^{-1}$ dependence. Such size-dependent transition has been predicted for the variation in H-P measurements assessed earlier for copper materials [27]. The transition occurs when the dislocation pile-up length is sufficiently reduced such that only one dislocation loop, $n=1.0$, is able to be produced within a restricted slip plane length to overcome the nano-polycrystal grain boundary resistance. On such a restricted dislocation number basis, the dislocation model description for an $\mathrm{H}-\mathrm{P}$ dependence connects with the described strength dependence of whiskers, nano-wires, and micro-pillars on their specimen diameters. 


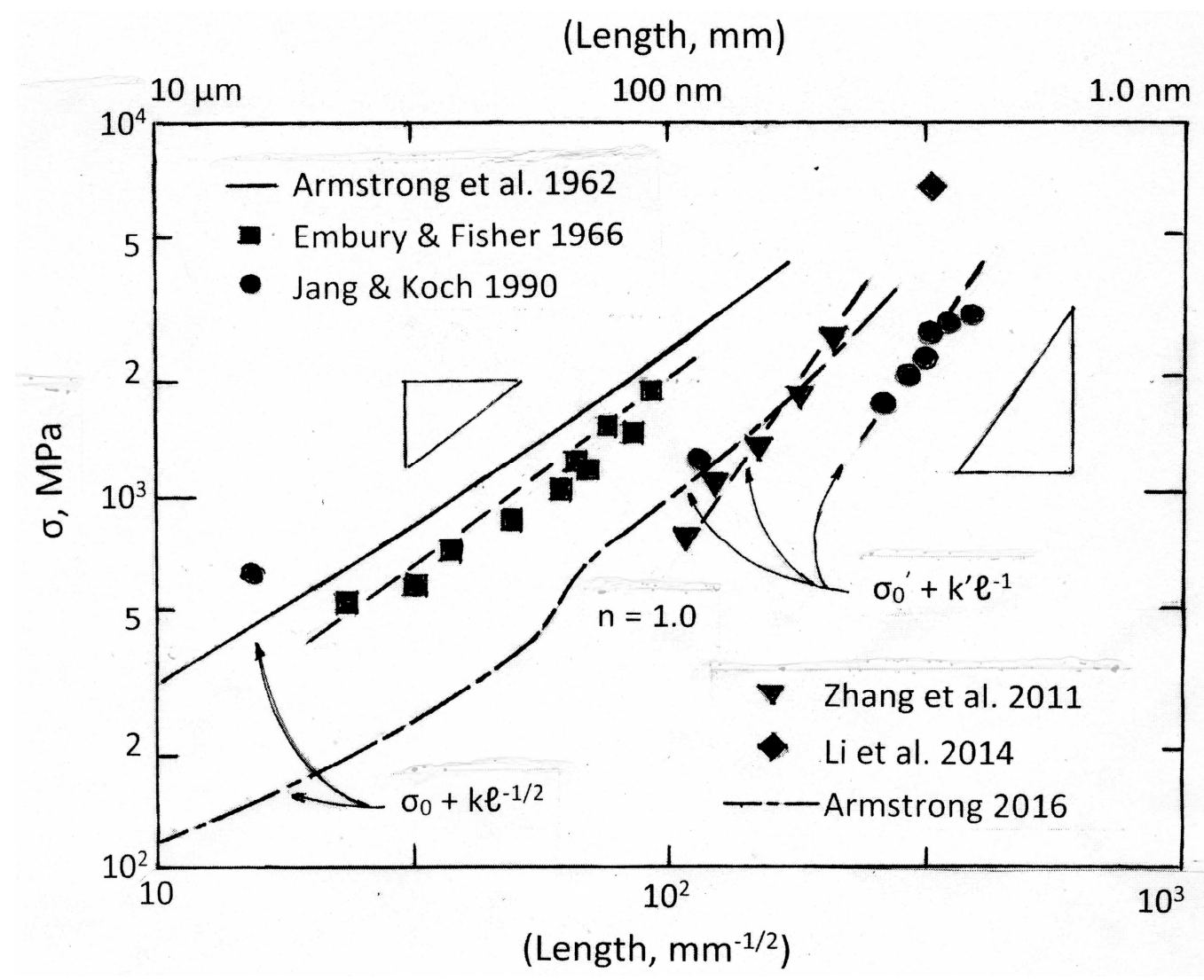

Figure 2. Strength of $\alpha$-iron and steel materials on the basis of an inverse square root of grain size dependence that transitions to an inverse size dependence depending on the level of the dislocation pile-up stress intensity; an expanded version of compiled results is reported in reference [26].

\section{Crystal Dislocation Pile-Ups at Small Dimensions}

The reduction in numbers of dislocations in pile-ups within ultrafine crystal or grain size materials raises an issue of analogous pile-up lengths and crack sizes associated with brittle fracturing of conventional microstructures. Petch determined an inverse square root of grain size dependence for the cleavage fracture strength of a combination of $\alpha$-iron and related steel materials with grain sizes larger than ten microns and also provided the now widely accepted explanation for the dependence in terms of the dislocation pile-up model [28]. Just afterwards, Stroh provided a follow-up calculation of the condition whereby the concentrated stress at the tip of the pile-up was the same as for a Griffith-type cleavage crack [29]. The similar relationship of crystal grain size and crack size dependencies for describing fracture strengths has been reviewed [30].

Figure 3 provides a comparison of the stress concentrations at a distance, $r$, ahead of two pile-ups and cracks for 5 and 49 dislocations in the pile-ups [12]. In the model figure description, $\tau_{23}$ and $\tau_{\infty}$ are the local shear stress and applied shear stress; $A_{i}$ is dislocation position within the pile-up divided by the characteristic length, $a^{\prime}=G b / 2 \pi \tau_{\infty}$, in which $G$ is the shear modulus and $b$ is dislocation the Burgers vector. The $n=5$ and $n=49$ open circles point to the level of the stress ratios at the pile-up tips. The Griffith stress concentration follows an $r^{-1 / 2}$ dependence as expected and is approximately followed at small $\left(r / a^{\prime}\right)$ by the forward pile-up stress concentration. At large $\left(r / a^{\prime}\right)$, the pile-up stress concentration is seen to follow an $r^{-1}$ dependence as is sometimes employed to represent the pile-up as a multiple Burgers vector dislocation of strength, $n b$. 


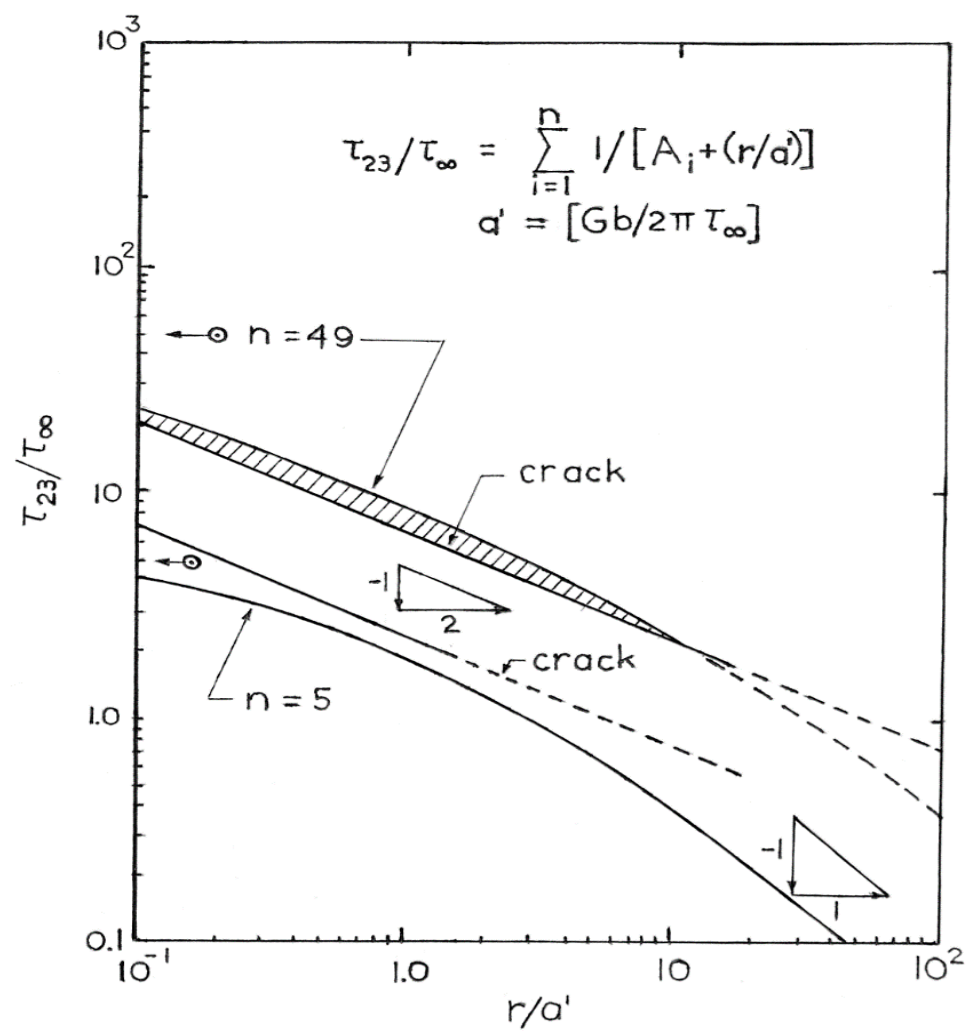

Figure 3. Comparison of the concentrated stresses ahead of dislocation pile-ups consisting of 5 or 49 dislocations and Griffith cracks of equal lengths [12].

The notable result shown in Figure 3 is that the smaller dislocation pile-up does not achieve a sufficient stress concentration to be modeled as a Griffith crack. On such theoretical basis, therefore, one might expect that cleavage would be more difficult to initiate within an ultrafine grain size material. In fact, experimental evidence for the greater difficulty of initiating cleavage in ultrafine grain size $\alpha$-iron material has been reported by Hohenwarter and Pippan [31]. The result adds to the well-known experimental observation of lowering the ductile-to-brittle transition behavior of steel and related bcc metals through refinement of the polycrystal grain size, particularly via measurements obtained in Charpy impact testing [30].

\section{Crystal Size-Dependent Strain Rate Sensitivity}

A dislocation mechanics description of loading rate dependence based on thermally-activated dislocation motion has provided a valuable additional avenue for the investigation of crystal size effects at micro- to nano-scale sizes. An early model description of the behavior for conventional grain size hcp cadmium involved separation of the strain rate sensitivity property into grain volume and grain boundary components in the relation [32]:

$$
\left(1 / v^{*}\right)=\left(1 / v_{0}^{*}\right)+\left(k_{\varepsilon} / 2 \mathrm{~m}_{\mathrm{T}} \tau_{\mathrm{C}_{\mathrm{C}}}\right) \ell^{-1 / 2}
$$

The parameters in Equation (1) are an activation volume, $\left.v^{*}=A^{*} b=k_{B} T[\{\Delta \ln (d \gamma / d t)\} / \Delta \tau\}\right]_{T}$, in which $A^{*}$ is an activation area; $k_{B}$ is Boltzmann's constant; $T$ is temperature; $\Delta \ln (d \gamma / d t)$ is the imposed change in the plastic shear strain rate; $\Delta \tau$ is the accompanying change in shear stress; $k_{\varepsilon}$ is the $\mathrm{H}-\mathrm{P}$ stress intensity, $m_{T}$ is the Taylor orientation factor; $\tau_{C}$ is the local shear stress at the grain boundary; and $\ell$ is the grain size. The first term, $\left(1 / v_{0}^{*}\right)$, measures the rate-dependent contribution of the dislocation motion within the grain volume and the second term, involving the factor $\left(1 / \mathrm{vC}^{*}\right)$, is a measure of the thermally-activated resistance to transmission of plastic flow across the grain boundary [33]. The product $\left(\tau_{C}{ }^{v} C^{*}\right)$ is constant, and thus Equation (1) follows an H-P type dependence. 
The current Figure 4 is an added-to version of a previous description of copper and nickel measurements in which a comparison was made with the Hall-Petch type grain size prediction given in Equation (1) [34]. The upper curve in the figure is for $\mathrm{T}=195 \mathrm{~K}$ and the lower curve for $300 \mathrm{~K}$. Transition from grain size strengthening to weakening is shown to occur in the smaller grain size regime at the "jump" in the filled-triangle values of $\left(1 / v^{*}\right)$. The unmistakable jump by an approximate order-of-magnitude leads to $v^{*}$ values of near atomic dimensions that are generally determined for higher temperature (creep) deformations. However, additional open circle points shown in the figure, as obtained from measurements reported by Chen et al. [35], are seen to follow the H-P grain size strengthening prediction. The positions of these points near to the H-P dependence are significant in terms of the grain boundary structures being stable and continuing to resist slip transmission from within the grains. These same authors provided confirmation of $\mathrm{H}-\mathrm{P}$ grain size strengthening via separately reported hardness measurements. In related research on nano-grained copper and nickel materials, Zhou et al. have given emphasis to the importance of establishing thermal stability of the grain boundary structures in such materials [36]. Otherwise, Figure 4 shows $v^{*}$ to be an effective monitor for detecting the onset of grain size weakening, for example, in line with the determination of material creep behavior as described in a previous report by Armstrong et al. [37].

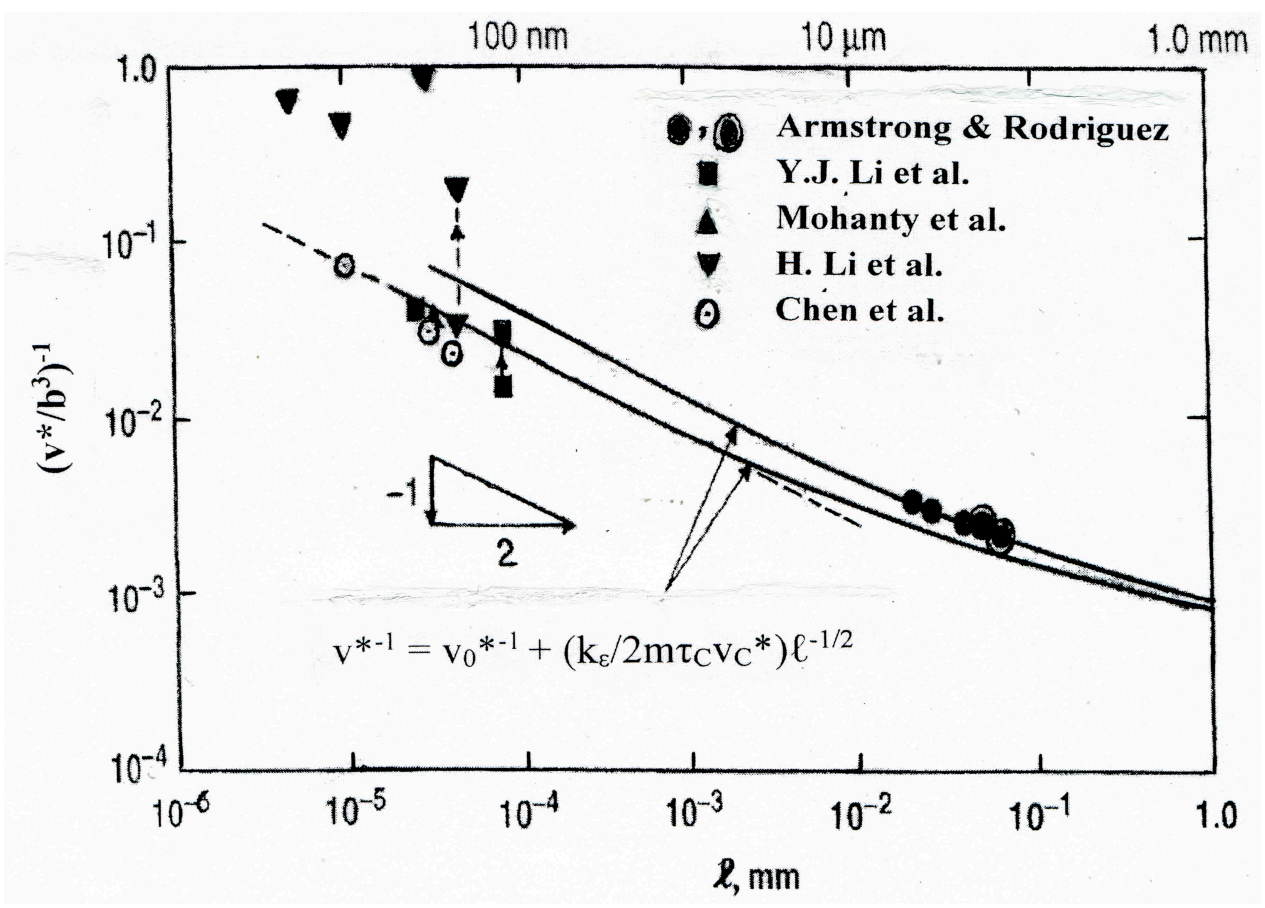

Figure 4. Strain rate sensitivity-based reciprocal activation volume measurements for copper and nickel materials spanning conventional and micro- to nano-scale grain sizes [34,35].

\section{Discussion}

The present description of experimental strength measurements involved examples, in turn, of the topics: localized deformations in micro- and nano-indentation tests; tensile or compression tests of whisker, micro-wire, and micro-pillar crystal or polycrystalline specimens; and stress-strain, fracturing, and deformation rate dependencies of micro-to nano-polycrystalline materials. In a number of cases, the micro- or nano-scale properties have been connected with (lower) strength levels normally achieved in conventional bulk materials.

An example of connection between nano-indentation testing incorporated in Figure 1 and technical alloy development has been given in a report on aluminum single crystals by Filippov and Koch [38]. The test method was employed to probe the material anisotropic elastic deformation behavior through testing the diamond pyramid hardness of (100), (110), and (111) crystal surfaces. The research 
relates to reference [20] in which a comparison was made between the experiment and simulation of nano-indentations in (111) and (100) $\alpha$-iron crystal surfaces. At an opposite dimensional scale, an important civil engineering connection spanning nano- to macro-size dimensions was provided by a comparison of the ultrafine steel wire measurements described for the drawn micro-wire strengths presented in Figure 2 and the comprehensive description by Ono [39] of steel wire materials employed in historical and current transportation bridge constructions.

A novel example of exceptionally high strength measurements being made on silicon nano-particles, relating to the results shown in Figure 1, has been reported by Nowak et al. [40]. Near theoretical limiting strength levels were determined by compression of the particles between hardened steel platens. In another study, so-called length-scale 'architectured' polycrystalline copper micro-pillars have been fabricated with an achievement of surprisingly higher strength advantage [41]. Another useful study of micro-pillars has involved the measurement of solute effects in aluminum alloys [42]. Basic features of slip behavior have been reported for Fe-3\% Si micro-pillar crystals [43]. Dendrite/nano-structured (high entropy alloy) titanium-based composite material has been investigated in static and dynamic compression tests [44]. The use of probing spherical nano-indentation hardness testing has been applied as far afield as in the evaluation of the elastic modulus and strain energy within the mineral, antigorite, to understand planetary tectonic plate subduction behavior [45], thus spanning the seemingly largest imaginable range in dimensions.

Finally, in discussion, the several examples presented of dislocation mechanics modeling of hardness, stress-strain, fracturing, and strain rate sensitivities of materials at smaller dimensions have focused on particular features accompanying the behavior of single or small groups of dislocations. The higher strength levels and exceptional strain hardening behaviors can be understood in a general manner in terms of the higher values of internal dislocation stresses accompanying smaller dislocation line lengths and smaller separations accompanying subsequent dislocation interactions. Stress levels approaching the theoretical strength are obtained [46], for example, as indicated in Figure 2, for the smallest effective grain size of heavily drawn eutectoid steel wire material [7].

\section{Summary}

This opening editorial report is presented for the current Crystals journal Special Issue on the topic of "Crystal Plasticity at Micro- and Nano-Scale Dimensions". A number of example references are provided to demonstrate current research interests in the topic. Four particular descriptions of microto nano-strength property evaluations are given and are compared with conventional material strength properties. The dislocation mechanics-based model descriptions of the strength properties are based on the nucleation of dislocations and their interactions at corresponding micro- to nano-scale dimensions.

Author Contributions: This editorial has been jointly written by both co-authors. All authors have read and agreed to the published version of the manuscript.

Acknowledgments: The authors express appreciation to Dancy Yu for editorial assistance.

Conflicts of Interest: The authors declare no conflict of interest.

\section{References}

1. Vollertsen, F.; Biermann, D.; Hansen, H.N.; Jawahir, I.S.; Kuzman, K. Size effects in manufacturing of metallic components. CIRP Ann.-Manufact. Tech. 2009, 58, 566-587. [CrossRef]

2. Asano, K.; Tang, H.; Chen, C.-Y.; Nagoshi, T.; Chang, T.-F.; Yamane, D.; Konishi, T.; Machida, K.; Masu, K.; Sone, M. Promoted bending strength in micro-cantilevers composed of nano-grained gold toward MEMS applications. Microelect. Eng. 2018, 196, 20-24. [CrossRef]

3. Cheng, C.; Wan, M.; Meng, B.; Zhao, R.; Han, W.P. Size effect on the yield behavior of metal foil under multiaxial stress states: Experimental investigation and modelling. Int. J. Mech. Sci. 2019, 151, 760-771. [CrossRef] 
4. Zhang, L.; Zhao, H.; Dai, Y.; Yang, Y.; Du, X.; Tang, P.; Zhang, L. Molecular dynamics simulation of deformation accumulation in repeated nanometric cutting on single-crystal copper. RSC Adv. 2015, 5, 12678-12685. [CrossRef]

5. Vorotilo, S.; Loginov, P.; Mishnaevsky, L.; Siderenko, D.; Levashov, E. Nano-engineering of metallic alloys for machining tools: Multiscale computational and in situ TEM investigation of mechanisms. Mater. Sci. Eng. A 2019, 739, 480-490. [CrossRef]

6. Brenner, S.S. Properties of whiskers. In Growth and Perfection of Crystals; Doremus, R.H., Roberts, B.W., Turnbull, D., Eds.; John Wiley \& Sons, Inc.: New York, NY, USA, 1958; pp. 157-190.

7. Li, Y.; Raabe, D.; Herbig, M.; Choi, P.-P.; Goto, S.; Kostka, A.; Yarita, H.; Borchers, C.; Kirchheim, R. Segregation stabilizes nano-crystalline bulk steel with near theoretical strength. Phys. Rev. Lett. 2014, 113, 106104. [CrossRef]

8. Rogne, B.R.S.; Thaulow, C. Strengthening mechanisms of iron micro-pillars. Philos. Mag. A 2015, 95, 1814-1828. [CrossRef]

9. Wheeler, J.M.; Kirchlechner, C.; Micha, J.-S.; Michler, J.; Kiener, D. The effect of size on the strength of FCC metals at elevated temperatures: Annealed copper. Phil. Mag. 2016, 96, 3379-3395. [CrossRef]

10. Armstrong, R.W.; Chou, Y.T.; Fisher, R.M.; Louat, N. The limiting grain size dependence of the strength of a polycrystalline aggregate. Phil. Mag. 1966, 14, 943-951. [CrossRef]

11. Li, J.C.M.; Liu, G.C.T. Circular dislocation pile-ups: I. Strength of ultrafine polycrystalline aggregates. Phil. Mag. 1967, 15, 1059-1063. [CrossRef]

12. Armstrong, R.W. Hall-Petch analysis for nano-polycrystals. In Nano-Metals—Status and Perspective; 33rd Risö International Symposium on Materials Science; Fæster, S., Hansen, N., Huang, X., Juul Jensen, D., Ralph, B., Eds.; Technical University of Denmark: Roskilde, Denmark, 2012; pp. 181-199.

13. Hughes, G.D.; Smith, S.D.; Pande, C.S.; Johnson, H.R.; Armstrong, R.W. Hall-Petch strengthening for the micro-hardness of twelve nanometer grain diameter electrodeposited nickel. Scr. Metall. 1986, 20, 93-97. [CrossRef]

14. Armstrong, R.W.; Mecholsky, J.J.; Shin, H.; Tsai, Y.L. Elasticity, plasticity and cracking at indentations in single crystal silicon. J. Mater. Sci. Letts. 1993, 12, 1274-1275. [CrossRef]

15. Pethica, J.B.; Hutchings, R.; Oliver, W.R. Hardness measurement at penetration depths as small as $20 \mathrm{~nm}$. Phil. Mag. 1983, 48, 593-606. [CrossRef]

16. Wan, H.; Shen, Y.; Chen, Q.; Chen, Y. A plastic damage model for finite element analysis of cracking of silicon under indentation. J. Mater. Res. 2010, 25, 2226-2236. [CrossRef]

17. Bradby, J.E.; Williams, J.S.; Wong-Leung, J.; Swain, M.V.; Munroe, P. Mechanical deformation in silicon by micro-indentation. J. Mater. Res. 2001, 16, 1500-1507. [CrossRef]

18. Armstrong, R.W.; Elban, W.L. Exceptional crystal strain hardening determined over macro- to micro- to nano-size scales in continuous spherical indentation tests. Mater. Sci. Eng. A 2019, 757, 95-100. [CrossRef]

19. Armstrong, R.W.; Elban, W.L. Tungsten (111) crystal strain hardening in nano-indentations. Int. J. Refract. Met. Hard Mater. 2020, 87, 105140. [CrossRef]

20. Armstrong, R.W.; Elban, W.L. Dislocation reaction mechanism for enhanced strain hardening in crystal nano-indentations. Crystals 2020, 10, 9. [CrossRef]

21. Yang, H.K.; Cao, K.; Han, Y.; Wen, M.; Guo, J.M.; Tan, Z.L.; Lu, J.; Lu, L. The combined effects of grain and sample sizes on the mechanical properties and fracture modes of gold micro-wires. J. Mater. Sci. Tech. 2019, 35, 76-83. [CrossRef]

22. Guo, S.; He, Y.; Li, Z.; Lei, J.; Liu, D. Size and stress dependences in the tensile stress relaxation of thin copper wires at room temperature. Int. J. Plast. 2019, 112, 278-296. [CrossRef]

23. Yuan, L.; Xu, C.; Shivpuri, R.; Shan, D.; Guo, B. Size effect in the uniaxial compression of polycrystalline Ni nanopillars with small number of grains. Metall. Mater. Trans. A 2019, 50A, 4462-4479. [CrossRef]

24. Shahbeyk, S.; Voyiadjis, G.Z.; Habibi, V.; Astaneh, S.H.; Yaghoobi, M. Review of size effects during micro-pillar compression test: Experiments and atomistic simulations. Crystals 2019, 9, 591. [CrossRef]

25. Kiener, D.; Fritz, R.; Alfreider, M.; Leitner, A.; Pippan, R.; Maier-Kiener, V. Rate limiting deformation mechanisms of bcc metals in confined volumes. Acta Mater. 2019, 166, 687-701. [CrossRef]

26. Armstrong, R.W. Crystal engineering for mechanical strength at nano-scale dimensions. Crystals 2017, 7, 315. [CrossRef] 
27. Armstrong, R.W.; Smith, T.R. Dislocation pile-up predictions for the strength properties of ultrafine grain size fcc metals. In Processing and Properties of Nanocrystalline Materials; Suryanarayana, C., Singh, J., Froes, F.H., Eds.; TMS-AIME: Warrendale, PA, USA, 1996; pp. 345-354.

28. Petch, N.J. The cleavage strength of polycrystals. J. Iron Steel Inst. 1953, 174, 25-28.

29. Stroh, A.N. The formation of cracks as a result of plastic flow. Proc. R. Soc. (Lond.) A 1954, 223, 404-414.

30. Armstrong, R.W. Material grain size and crack size influences on cleavage fracturing. Phil. Trans. R. Soc. (Lond.) A 2015, 373, 20140124. [CrossRef]

31. Hohenwarter, A.; Pippan, R. Anisotropic fracture behavior of ultrafine-grain iron. Mater. Sci. Eng. A 2010, 527, 2649-2656. [CrossRef]

32. Prasad, Y.V.R.K.; Armstrong, R.W. Polycrystal versus single-crystal strain rate sensitivity of cadmium. Phil. Mag. 1974, 29, 1421-1425. [CrossRef]

33. Armstrong, R.W.; Rodriguez, P. Flow stress/strain rate/grain size coupling for fcc nano-polycrystals. Phil. Mag. 2006, 86, 5787-5796. [CrossRef]

34. Armstrong, R.W. Size effects on material yield strength/deformation/fracturing properties. J. Mater. Sci. 2019, 1-16. [CrossRef]

35. Chen, J.; Lu, L.; Lu, K. Hardness and strain rate sensitivity of nano-crystalline Cu. Scr. Mater. 2006, 54, 1913-1918. [CrossRef]

36. Zhou, X.; Li, X.Y.; Lu, K. Enhanced thermal stability of nano-grained metals below a critical grain size. Science 2018, 360, 526-530. [CrossRef] [PubMed]

37. Armstrong, R.W.; Conrad, H.; Nabarro, F.R.N. Meso-to-nano-scopic polycrystal/composite strengthening. In Mechanical Properties of Nano-Structured Materials and Nano-Composites; Ovid'ko, I., Pande, C.S., Krishnamoorti, R., Lavernia, E., Skandan, G., Eds.; Mater. Res. Soc.: Warrendale, PA, USA, 2004; pp. 69-77.

38. Filippov, P.; Koch, U. Nano-indentation of aluminum single crystals: Experimental study on influencing factors. Materials 2019, 12, 3688. [CrossRef] [PubMed]

39. Ono, K. Size effects of high strength steel wires. Metals 2019, 9, 240. [CrossRef]

40. Nowak, J.D.; Beaber, A.R.; Ugurlu, O.; Girshick, S.L.; Gerberich, W.W. Small size strength dependence on dislocation nucleation. Scr. Mater. 2010, 62, 819-822. [CrossRef]

41. Hou, X.D.; Krauss, S.; Merle, B. Additional strengthening in length-scaled architectured copper with ultrafine and coarse domains. Scr. Mater. 2019, 165, 55-59. [CrossRef]

42. Yan, S.; Zhou, H.; Qin, Q.H. Microstructure versus size: Nano/micro-scale deformation of solute-strengthening $\mathrm{Al}$ alloys via pillar compression tests. Mater. Res. Lett. 2019, 7, 53-59. [CrossRef]

43. Kheradmand, N.; Rogne, B.R.; Dumoulin, S.; Deng, Y.; Johnsen, R.; Barnoush, A. Small scale testing approach to reveal specific features of slip behavior in bcc metals. Acta Mater. 2019, 174, 142-152. [CrossRef]

44. Dong, J.L.; Wang, Z.; Han, L.N.; Tang, Y.L.; Qiao, J.W.; Shi, X.H.; Wang, Z.H. Novel in-situ Ti-based dendrite/nano-structured matrix composites with excellent mechanical performances upon dynamic compression. J. Alloy Compounds 2019, 781, 716-722. [CrossRef]

45. Hansen, L.N.; David, E.C.; Brantut, N.; Wallis, D. Insight into the micro-physics of antigorite deformation from spherical nano-indentation. Phil. Trans. R. Soc. (Lond.) A 2020, 378, 20190197.

46. Han, W.-Z.; Huang, L.; Ogata, S.; Kimizuka, H.; Yang, Z.-C.; Weinberger, C.; Li, Q.-J.; Liu, B.-Y.; Zhang, X.X.; $\mathrm{Li}$, J.; et al. From "Smaller is stronger" to "Size-independent strength plateau": Towards measuring the ideal strength of iron. Adv. Mater. 2015, 27, 3385-3390. [CrossRef] [PubMed]

(C) 2020 by the authors. Licensee MDPI, Basel, Switzerland. This article is an open access article distributed under the terms and conditions of the Creative Commons Attribution (CC BY) license (http://creativecommons.org/licenses/by/4.0/). 